\title{
ENSINO DO LUGAR E AS IMAGENS DOS ESTUDANTES DA EDUCAÇÃO BÁSICA SOBRE FEIRA DE SANTANA/BA
}

\author{
Eliete dos Santos Lopes ${ }^{1}$ e Celia Regina Batista dos Santos ${ }^{2}$ \\ 1. Bolsista PIBIC/CNPq, Graduanda em Geografia, Universidade Estadual de Feira de Santana, e-mail: \\ elietelopes94@gmail.com \\ 2. Orientadora, DEDU- Departamento de Educação, Universidade Estadual de Feira de Santana, e-mail: \\ beltrano@provedor.br
}

PALAVRAS-CHAVE: Ensino do lugar; Mapas Mentais; Feira de Santana.

\section{INTRODUÇÃO}

No ensino de Geografia o desenvolvimento de mapas mentais tem por objetivo entender como os alunos compreendem o lugar onde vivem, conhecer os valores previamente desenvolvidos por eles e avaliar a imagem que eles têm do seu lugar (CAVALCANTE, 1998). Diante disso, a presente pesquisa tem como objetivo geral analisar as imagens sobre Feira de Santana evidenciadas em mapas mentais elaborados por alunos da educação básica, verificando possíveis articulações entre suas imagens e a forma como os professores abordam o conceito de lugar nas aulas de Geografia. Para alcançar o principal objetivo tem-se como perguntas norteadoras: quais compreensões, imagens, valores podem ser evidenciados nos mapas mentais desenvolvidos por alunos da educação básica em relação aos bairros onde moram e ao lugar Feira de Santana? O que os alunos da educação básica entendem por lugar? O estudo desse conceito é trabalhado nas aulas de Geografia? Como os professores investigados conceituam lugar e como fazem essa abordagem em suas aulas? Quais as imagens dos alunos sobre Feira de Santana?

O presente plano de pesquisa se articula com o projeto "Lugar, Formação Docente e Elaboração de Material Didático-Pedagógico sobre Feira de Santana, Ba” na medida em que busca averiguar as imagens sobre Feira de Santana apresentadas nos mapas mentais de estudantes da educação básica e como os docentes fazem a mediação pedagógica sobre o ensino do lugar e o lugar de vivência dos estudantes, neste caso, Feira de Santana.

\section{PERCURSO METODOLÓGICO}

Para facilitar o desenvolvimento da pesquisa, ela foi dividida em etapas; na primeira ocorreu o levantamento bibliográfico debruçado no tema abordado na busca de elaborar o arcabouço teórico com base na problemática, objetivos e principais conceitos debatidos no decorrer de todo o processo, sendo que os mesmos foram encontrados em teses, livros, artigos científicos e monografias com abordagem sobre mapas mentais, lugar, ensino de geografia, imagem, dentre outros; os principais autores que participaram da discussão dos conceitos foram os seguintes: Ferreira, Pereira e Santos (2014), Barbosa e Neto (2010), Pauli (2012), Girão e Lima (2013), Oliveira (2014), Callai (2010).

Concomitantemente aconteceu a elaboração do instrumento de pesquisa, os questionários, com perguntas direcionadas para os alunos do Ensino Fundamental II da escola municipal. $O$ intuito era coletar informações sobre o conceito de lugar, a elaboração de mapas mentais, sua utilização, a relação dos conteúdos com o lugar de vivência, entre outras questões. Após a coleta de dados prosseguimos com a organização, tabulação e análise dos dados para, em seguida, elaboração do relatório. 


\section{ACHADOS DA PESQUISA \\ 4.1 Perfil dos sujeitos investigados}

Como já havia sido citado em outros pontos da pesquisa, os investigados foram alunos do Ensino Fundamental II, de uma escola municipal, de um determinado bairro da cidade apresentada. A pesquisa foi desenvolvida com 55 discentes com aplicação de questionário e uma entrevista informal com alunos de uma turma do $9^{\circ}$ ano com a mesma perspectiva. Vale ressaltar que para melhor organização da tabulação de dados, ocorreu uma classificação dos discentes de D1 até D55, pois diante da quantidade isso colaborou na identificação de cada sujeito.

O processo foi desenvolvido com alunos na faixa etária entre 11 e 15 anos de idade, distribuídos entre o $6^{\circ}$ e $9^{\circ}$ ano; como eles já passaram por séries anteriores, é possível relatar as experiências obtidas nos anos que antecederam a série atual. No que diz respeito a nascimento, naturalidade e moradia, 46 alunos nasceram na cidade de Feira de Santana, mas 13 deles não moram nesse lugar desde que nasceram, desses, alguns moram entre $1-3$ anos, outros há mais de 6 anos; 7 são naturais de outros lugares, como Salvador, Aracajú, Tanquinho, Rio de Janeiro, São Paulo, Bonfim de Feira, entre outros; vale destacar que apenas 1 estudante respondeu que não é natural do lugar aqui abordado e também não disse onde nasceu, contudo mora entre $1-3$ anos.

\subsection{Conceito de lugar na perspectiva dos estudantes}

Dos sujeitos investigados, ao questionar o que eles entendem por lugar, inicialmente apresentaram duvidas, mas em seguida o termo foi explicado para esclarecimento, assim como as demais questões propostas e dessa forma foi possível perceber que são diversas formas de entendimento, conforme pode ser visualizada a seguir:

\begin{tabular}{|c|l|}
\hline Sujeitos & \multicolumn{1}{c|}{ Quadro 1. Conceito de lugar na perspectiva dos estudantes } \\
\hline D1 & Eu entendo que "lugar" é onde eu vivo, onde nós vivemos \\
\hline D3 & É qualquer ambiente onde nós vivemos \\
\hline D5 & É um espaço de vivência e relações com outras pessoas no dia a dia \\
\hline D10 & $\begin{array}{l}\text { O lugar que me sinto pertencente, nas baias de cavalos montando e levando } \\
\text { a vida }\end{array}$ \\
\hline D12 & É todo espaço de vivencia \\
\hline D14 & É um lugar que eu gosto \\
\hline D19 & $\begin{array}{l}\text { Eu entendo que lugar é o bairro que moro, minhas intimidades com as } \\
\text { pessoas }\end{array}$ \\
\hline D21 & O que eu entendo o que é lugar é onde eu moro \\
\hline D23 & Onde gente mora \\
\hline D25 & $\begin{array}{l}\text { Entendo que lugar é saber a rua que você mora, saber o que tem na rua, } \\
\text { bairro, casas }\end{array}$ \\
\hline D29 & Meu lugar é minha casa \\
\hline D30 & E todo aquele lugar que é paisagem: minha casa, escola etc \\
\hline D43 & Que tem casas, carros \\
\hline D44 & Local, ambiente, destino, espaço geográfico terrestre, etc \\
\hline D47 & Nada \\
\hline D49 & Nada \\
\hline D52 & $\begin{array}{l}\text { Quando não tem muitas mortes, quando faço amizades, quando o lugar e } \\
\text { bom de morar }\end{array}$ \\
\hline D55 & Nada \\
\hline
\end{tabular}


Fonte: Pesquisa de campo realizada entre os meses 05 e 06 de 2018

Elaboração da autora

Como pode ser observado no quadro 1, existem versões e conceitos diversificados a respeito do lugar; formando algumas categorias de acordo com as definições: alunos que vinculam lugar a valorização do mesmo, pertencimento, moradia, espaço de vivência, paisagem, relações de convivência e tiveram aqueles que não responderam, deixaram realmente em branco ou colocaram nada, ou seja, o lugar para esses discentes é conceituado como nada.

\subsection{Importância de estudar o lugar de vivência nas aulas de geografia na opinião dos sujeitos investigados}

Pôde-se observar e concluir que do número geral de alunos, a maioria considera importante a abordagem do lugar de vivência nas aulas, principalmente por ser o lugar onde convivem, moram, seja ele o bairro ou a cidade. É relevante dizer que dos 55 investigados 37 alegaram que é importante e apenas 9 desses não justificaram a sua afirmação; e 18 consideram que não, sendo que 3 justificaram e 15 apenas disseram que não, isso pode ser simplesmente porque não quiseram responder ou por não entenderam e reconhecerem o quão necessário é se informar sobre o lugar considerado por eles.

Em relação a já ter estudado sobre Feira de Santana nas aulas de Geografia ou em aulas de outras disciplinas, apenas 17 estudantes responderam que isso nunca foi visto. Pelas afirmativas, pode-se concluir que a temática lugar é exposta pelos professores de forma bastante tradicional, com explicação, apontamentos no quadro, atividades, pesquisas escritas; alguns argumentaram que trabalharam com imagens, maquetes, vídeos, projetos e foram exatamente esses que esclareceram o quanto gostaram, se sentiram atraídos pela aula, ou seja, quando a mediação ocorre de maneira dinâmica, com novidades, o educador consegue despertar o interesse da turma pelo ideia apresentada, mas infelizmente, isso na maioria das vezes não acontece.

\subsection{Os saberes dos investigados sobre mapas mentais e a imagem deles sobre Feira de Santana}

Ficou esclarecido que pouquíssimos alunos sabem o que é mapa mental, não sabem do que se trata e que os professores não utilizam esse meio para mediar suas aulas, sendo que isso se encaixa tanto para Geografia, quanto para as demais disciplinas. Dos 55 discentes, 10 responderam algo um pouco mais relacionado a temática, 12 afirmaram não entender nada sobre o assunto e 33 não responderam.

Com tudo isso conclui-se que os alunos do Ensino Fundamental II praticamente não entendem nada a respeito de mapas mentais, provavelmente porque o mesmo não é exposto durante as aulas para uma melhor explicação dos conteúdos.

Em relação a imagem que os sujeitos investigados possuem sobre Feira de Santana, com base nos dados colhidos, confirmou-se que os estudantes consideram essa cidade como algo relacionado ao lazer, essa é a imagem que eles possuem diante da cidade aqui abordada.

\subsection{Relações dos alunos para com o lugar Feira de Santana}

Os estudantes investigados, fazendo uma análise geral, gostam da cidade de Feira de Santana, tem algum tipo de sentimento por ela, como por exemplo, carinho, amizade, afeto, amor e maioria justificam dizendo que é uma cidade boa, tranquila, que gostam da mesma porque nasceram aqui, ou seja, essas pessoas se sentem pertencentes a esse lugar, tem uma relação de pertencimento, se identificam. Ressaltando que 
discentes que responderam de forma negativa, isto é, não gostam da cidade, relataram sobre a violência existente.

\section{CONSIDERAÇÕES FINAIS}

De acordo com a análise dos dados coletados, foi possível verificar que os estudantes reconhecem a importância de estudar os seus lugares de vivência, mas que os mestres não exercem a mediação com o uso dos mapas mentais, pois os investigados praticamente não sabem o que é e nem a sua função, pouquíssimos deles conseguiram responder as perguntas relacionadas a mapas mentais, e talvez isso seja resultado da explanação das questões no momento da aplicação do instrumento de pesquisa. O lugar de vivência é trabalhado nas aulas de Geografia, ciências, história e artes através de vídeos, maquetes, imagens, contexto histórico, desenhos; apenas 7 sujeitos afirmaram que o professor ou professora usaram mapa metal como instrumentos de mediação nas aulas.

As imagens que os estudantes têm de Feira de Santana é que ela simboliza um lugar de lazer, onde podem ficar à vontade, passear, se divertir, em locais como shopping, parques, lagoas, cinema, praças, entre outros

\section{REFERÊNCIAS}

ARCHELA, Rosely Sampaio; GRATÃO, Lucia Helena B; TROSTDORF, Maria A.S. O lugar dos mapas mentais na representação do lugar. Geografia - Londrina, 2004.

CALLAI, Helena Copetti. Escola, cotidiano e lugar. Brasília, 2010

OLIVEIRA, Christian Dennys Monteiro de. Sentido da Geografia escolar. Fortaleza: Edições UFC, 2010.

GIRÃO, Osvaldo; LIMA, Surama Ramos. O ensino de Geografia versus leitura de imagens: resgate e valorização da disciplina pela "alfabetização do olhar". Geografia, Ensino e Pesquisa, v. 17, n. 2, maio/ago. 2013.

LIMA, Angélica Macedo Lozano, KOZEL, Salete. Lugar e mapa mental: uma análise possível. V. 18, n. 1, 2009.

NETO, Francisco Otávio Landim; DIAS, Raimundo Helion Lima. Mapas mentais e a construção de um ensino de Geografia significativo: Algumas reflexões. Revista Eletrônica Geoaraguaia. Barra do arças-MT. V1, n1, p.1-12 jan/julho, 2011.

OLIVEIRA, Christian Dennys Monteiro de. Sentido da Geografia escolar. Fortaleza: Edições UFC, 2010.

OLIVEIRA, Maxwell Ferreira de. Metodologia Científica: um manual para a realização de pesquisas em administração. Catalão: UFG, 2011.

PAULI, Willian Marques. O ensino de Geografia e as novas possibilidades pedagógicas construídas a partir da utilização de ambientes virtuais de aprendizagem. 2012.

SILVA, Onildo Araújo da. Geografia: metodologia e técnicas de ensino. Feira de Santana, 2010. 